\title{
Ideological Reconfigurations: Privacy, Voyeurism and Form in Recent Malayalam Cinema
}

\author{
B. Abhijith \\ Research Scholar, Department of Cultural Studies, The English and Foreign Languages University, \\ Hyderabad, E-mail: aabhinov.91@gmail.com, ORCID id: https://orcid.org/0000-0002-8394-612X
}

\begin{abstract}
This paper traces a particular moment in the recent history of Malayalam Cinema when a shift in the representation of the private sphere was attempted. In the period after 2010, a set of new Malayalam films carried a shift in terms of aesthetics and narrative techniques and went on to unfold in a full-fledged manner by the end of the decade. The paper would look at Chappa Kurishu (Head or Tails, 2011), one of the early movies of this tide to shed light on the remarkable shift it achieves in representing the scenes of romantic and erotic intimacy on screen. As the narrative of the movie centers around the fight over a smart phone that ensues between two strangers in the city of Kochi, it gets entangled with questions of privacy, class and contest over the urban spaces. Bringing to the discussion contestations over the meanings of public and private manifested in certain urban-based movements in recent times like 'Kiss of Love' protests, it is argued that Chappa Kurishu can be read as a response to the contradictions arising out of the emergence of new subjects in the wake of urban transformations and the conflicting cinematic publics of multiplex and single hall theatre. The formal transactions between cinematic form and video form, the paper suggests, is one of the ways in which Chappa Kurishu attempts to respond to this situation in a way that signals the transitional position of the spectator subject.
\end{abstract}

Keywords: Malayalam Cinema, Voyeurism, Privacy, Video, Film Form

\section{Introduction}

There has been an evident shift in Malayalam cinema's relationship to the city space in recent times. The absence of a major city space within Kerala and the dominance of the rural in the ideological imaginations about the region resulted in a situation where thematic elements related to city have been suspended or remained subordinated. The cities outside Kerala provided the space for imagining the city or for invoking the village-city opposition (Radhakrishnan, 2017). This aesthetic paradigm has been inseparable from a spectator position which remained anchored within the ideological coordinates of the rural. However, new transformations are changing this scene and the city has come to occupy a central place in the narrative structure of Malayalam cinema in recent times. This process has been in correspondence with the dissemination of digital technology, redistribution of expertise in the wake of capitalist expansion and an increasing rate of urbanization. My focus is on the moment when this process attained a certain maturity and the thematic of city could be represented in a city within Kerala for the first time. As Ratheesh

This Open Access article is published under a Creative Commons Attribution Non-Commercial 4.0 International License (http://creativecommons.org/licenses/by-nc/4.0/), which permits non-commercial re-use, distribution, and reproduction in any medium, provided the original work is properly cited. For citation use the DOI. For commercial re-use, please contact editor@rupkatha.com. 
Radhakrishnan (2017) has suggested in his discussion of the emergence of 'Kochi film' as a genre, the city of Kochi has been the privileged site of this representation. Kochi witnessed the biggest urban growth in Kerala in recent times. In the post-2000 period linkages between credit markets, expatriate capital and real estate boom led to the unprecedented transformation of Kochi city. The consolidation of IT sector and arrival of ambitious projects like Smart City characterized the new process of urban space making (Varghese, 2017). In the Film Industry, the same period witnessed the production gradually getting relocated to Kochi from its earlier Madras-Trivandrum bases. A new crop of filmmakers and innovations in terms of narration, aesthetics and film technology emerged during this period. Needless to say, this process was mediated by the dissemination of digital technology and internet. The 'Kodambakkam era' when Madras (Today's Chennai), a metropolis outside the state, was the desired destination for aspirants who wanted to try their fortune in Malayalam cinema had completely transformed. The dissemination of digital and media technologies facilitated an increased exposure to films of all kinds produced across the world. If this world-cinema exposure was earlier restricted to certain film society groups and was considered a matter of 'taste', now it became a universal resource accessible to large number of people. This should also be seen in connection with an increasing urbanization of life and an expansion of middle class in Kerala.

Against this background, this paper analyses the representational dynamics and formal strategies employed in the movie Chappa Kurishu (Head or Tails, 2011) to make sense of the complex transactions between entrenching notions of privacy, saturation of digital technologies, emergence of autonomous sexual subjects and conflicting spectator positions. The paper suggests that the changing strategies of the representation of the private domain in Malayalam cinema and the attempt to position the spectator in a voyeuristic relation to this private domain have to be seen as ideological acts in response to the dissolution of traditional aesthetic paradigms on the one hand and social transformation on the other.

\section{Representation of the Private and Conflicting Spectator Slots}

Released in 2011, Chappa Kurishu was inspired by a Korean film Handphone (Han-min, 2009), attesting to the newly enabled exposure to world cinema discussed above. At the two end of the story are two youngsters with contrasting characters and backgrounds. One is Arjun (Fahad Fasil), a rich man who is in the ascending construction business of Kochi. And the other is Ansari (Vineeth Sreenivasan), a lower class Muslim with a rural north-Kerala background, who lives in a slum and works in a supermarket, doing odd jobs like sweeping and cleaning. Arjun stands for everything that an ambitious Kochi carries with it. He travels around and meets investors for new projects and goes extra mile to facilitate the expanding construction business in the city. He has an affair with his subordinate Sonia as he also prepares for his engagement with Ann, who is from a similar upper class family as his. In short, he is the new urban elite. Ansari, on the other hand, is a misfit in the new city. He looks shabby, lives in slum and is often looked down upon by his employer and others. The only appreciation and care for him come from Nafeesa, his co-worker in the supermarket for whom Ansari has a soft corner. The turn in the story is when Arjun misses his Apple iPhone and it accidently reaches Ansari's hand. Arjun is desperate to get the phone back as he has saved in the phone a video record of his own love-making moments with Sonia. Though 
3 | Ideological Reconfigurations: Privacy, Voyeurism and Form in Recent Malayalam Cinema

Ansari initially attempts to return the phone, he is pulled back by his inhibition and lack of proper communication skills. After a point of time, Ansari finds the possession of the smart phone to be giving him confidence, a sense of ownership over the world around him which is otherwise very hostile and merciless towards him. He delays his handing over of phone to Arjun, often to the frustration of latter. Ansari also uses it as an opportunity to get Arjun to do things for him, which he otherwise would not have been able to demand. By the time Ansari finally resolves to give the phone back, the worst scenario feared by Arjun had already happened. The video clip of the intimate scene had leaked through a café where Ansari had kept the phone and got uploaded on YouTube. Arjun losses his marriage alliance with Ann and an already embittered Sonia goes through the worse. Shattered as he is, Arjun finally manages to trace down Ansari and what follows is a reckless physical fight between them.

The movie simultaneously demonstrates the possibilities and threats offered by the digital technology. What endangers the privacy is the fact that Arjun recorded his own love making session with Sonia. The idea of recording it consists in a tendency to convert your own intimate moments into an object of visual consumption for yourself later. The elaborate manner in which the intimate scenes were depicted in Chappa Kurishu was unprecedented as far as Malayalam cinema was concerned. The lip to lip kissing on screen was first of its kind. The ideological dimension of this representational shift and its relation to the questions of subjectivity and spectatorship can be dealt with in relation to the discussion of the unwritten rule which prohibited kiss in Indian cinema undertaken by Madhava Prasad (1998). Prasad points to an unwritten rule that prohibited kissing in the Indian screen and examines the ideological underpinnings of the ban. One of the conventional explanations given in defence of the ban is one of cultural correspondence; that it is an expression of Indian culture as opposed to the western permissiveness. On the other hand, the opposite of this explanation is that of the 'enlightened critics' who see the violation of this ban itself as some kind of liberation. If kissing is not part of Indian culture, it raises the question what is the need to ban it. The very need to ban it points to the fact that 'culture is not as homogenous as it made out to be' (Prasad, 1998, pp. 90). Prasad argues that the 'ban reveals some dirty secrets of the state' (pp. 92). The form of the Indian state in which the bourgeoisie was only one of several participants and pre-capitalist ruling classes retained their privileges did not allow the representation of the private in public. Among all sexual displays, only kissing was prohibited points to the fact that kissing and details of sexual relations belong to the realm of the private. Representation of the private in the public would violate the scopic privileges of the pre-capitalist ruling class and the pre-modern patriarchal family because such a representation presupposes the circulation of men and women as autonomous sexual subjects and the dissolution of the pre-capitalist patriarchal enclave as the sanctioning authority. It threatens to define the couple as autonomous at the same time as it marks the modern state as the overseeing authority and guarantor of the couple's autonomy (pp. 97). Prasad adds that the moment of the representation of private in public also registers the coming into being of realist voyeurism.

The ideological effectiveness of the ban, however, can only be actualized by the active complicity of the spectator. Prasad cites the case of the audience reaction in cinema halls when the intimate scene proceeds beyond what is appropriate to maintain the community effect as a sign of this complicity. There would be shouts and comments from the crowd in the theatre, 
indicating the discomfort over the proceedings and the threat of spectator getting reminded of his voyeurism is thus overcome (pp. 104).

However, what we witness now is a transformation of this scenario as the multiplex, the new site of film exhibition, carries with it an individualized spectator, urban by definition, and guarantees the loneliness associated with capitalism inside the auditorium. This can also be seen as the dissolution of the earlier 'crowd' of cinema halls. The collective of the crowd is disappearing to make way for the individual spectator. It goes hand in hand with the location of the cinema hall among many of other consuming outlets in a mall. The logic of cinema as one commodity in the midst of many other commodities and the spectator as a consumer is firmly established within the multiplex. This doesn't mean that everyone who goes to multiplex to watch a film would be comfortably middle class, but the space functions as that of middle class aspiration (Athique, 2011). Adrian Athique, in his study focusing on the reconfiguration of the cinematic public in the wake of the spread of multiplexes, says:

"In a spatial sense, therefore, what is crucial for the multiplexes is that the crowd formed by the audience is absorbed into the building itself and is no longer publicly visible as a crowd, either to onlookers or amongst its members. Since the multiplex is divided amongst a number of auditoriums with staggered show-times, the multiplex audience is temporally dispersed, creating a cinema crowd that is no longer a potential mob occupying public space, but instead comprises a steady flow of consumers moving effortlessly and individually in private, commercial space" (pp. 155)

This is what engenders the conditions for realist voyeurism mentioned above. In her account of the voyeuristic relation to cinema, Laura Mulvey (1975) has argued that the separation of the object from the look directed towards it is central to the constitution of the active voyeuristic aspect of scopophilia. 'Although, the film is really being shown, is there to be seen, conventions of screening and narrative conditions give the spectator an illusion of looking on a private world' (pp. 9). This is enabled by a structure of spectation in which there is no longer a contractual coming together of the performer and the spectator, rather the contractual link is established between all members of the audience, including the filmmakers, outside the site of the performance (Prasad, 1998). This can turn the spectator into a voyeur as what is represented on screen is the world of private individuals just as the position of the spectator is now that of a private individual.

In the context of Kerala, the disintegration of the agricultural land relations, absence of industrial-capitalist developments and the consolidation of a service-sector middle class by 1970s resulted in the establishment of upper caste- middle class family as an ideal cultural unit of modernity. This was inseparable from the position the middle class family came to occupy as the central unit of consumption. There has been an accompanying structuring of the ideal spectator position of Malayalam cinema along the lines of the ethos of this middle class family (Radhakrishnan, 2010). At the level of representation, individual characters, including the lovers and couples, have mostly been subsumed into the moral universe of the parental family, preventing their free reign as independent subjects. The transformation of this scenario represented by Chappa Kurishu is that the new aspirations unleashed by global capitalism in the region asserts for a conception of men and women as autonomous sexual subjects. The voyeuristic 
5 | Ideological Reconfigurations: Privacy, Voyeurism and Form in Recent Malayalam Cinema

relation to cinema enabled by the individualized and isolated structure of spectation is coinciding with this. Interestingly, the voyeuristic relation Chappa Kurishu invites from the spectator is not that of the 'shamefaced voyeurism' (Metz, 1986) we hinted at earlier. In place of the illusion that one is looking in on to a private world, the scenes of sexual intimacy in Chappa Kurishu is coded as perverse through the act of the hero (or one of the two heroes) who records it in his phone. This helps to insulate the spectator from the threat of getting reminded of her own position as a voyeur into the private world of someone else. This shifting of the guilt from the spectator to the hero is suggestive of the ambiguity regarding spectator positioning. There is no assurance of the individualized spectatorship although a certain level of individualization is presupposed. It can be suggested that the threat of the pre-individual community affiliation within spectation is behind the attribution of guilt on the hero and the ordeals he goes through are punishments for his perversion. Instead of reminding the individual member of the audience about her own complicity in the existence of the contractual relation and creating an illusion for her that she is looking on a private world, the intimate scene is coded as an act of perversion in the movie, thereby negating the chances of shamefaced voyeurism. Breaking the conventions that governed Indian Cinema for long that included the prohibition of the kiss which Prasad discusses, Chappa Kurishu can be said to be one among the many films that are part of new awakening in many regional industries as part of the full-fledged capitalist turn in the subcontinent with glimpses of the transformation of subjectivity. However, the voyeuristic slot the movie presupposes for the spectator is only partial and is characterised by an ambiguity regarding the subject-positioning of the spectator.

There is a scene in the movie in which Nafeesa tells Ansari how superstar Mammootty looked so handsome in the movie Rajamanikyam (Rasheed, 2005) when she saw the movie the other day on a TV channel. After Nafeesa leaves, Ansari notices a large cut-out of the Movie Rajamanikyam in a corner of the road. He proceeds to a bike parked adjacent to it and looks in its mirror, combs his hair with his hands and smiles as if to imply that his look is also not that bad. When he does this, in the background is a cut-out of Rajamanikyam with a big image of Mammootty, the star, on it. On the one hand, this indicates the need for a symbolic supplement for Ansari to become a desirable person which is provided by the star's image in this case. On the other, it can be suggested, it gives a signal about two kinds of cinematic publics which are conflicting in their respective logics. One is the large single-hall theatre where the audience comes as large crowds, and all kinds of expressions such as shouting, howling, booing, etc. are possible. This is the site where mass-entertainers, like Rajamanikyam, featuring big stars, find their elevating ambiance. The second one is the one of the multiplex, which is in sync with autonomous individual subjectivity and which disapproves of the 'crowd behaviour'. Hence these two different logics of cinematic public are also coinciding with two logics of subjectivity.

\section{Kiss in the Streets: Privacy Figuring in Politics}

There are other sites where the resonance of this struggle over the meaning of privacy is more clearly manifested. The arrival of effective commodity logic carries with it an aspiration for the reconfiguration of the public space in a manner conducive for the allocation of the private sphere constituted by autonomous individual subjects. This reorganization doesn't entertain any interference of any community logic within it. Here, the possible villains are not only the pre- 
capitalist patriarchal enclaves, but also the masses that fall outside this newly constituted sphere of the private and are still tied to community affiliations. In this connection, it is interesting to take notice of the fact that three years after the release of Chappa Kurishu, a series of urban-centric protests erupted in Kerala which were popularly called 'Kiss of Love' protests. What triggered the protest was an incident happened in Kozhikode city. Members of Bharatiya Janatha Yuva Morcha, the youth wing of Bharathiya Janataha Party, vandalized a food café in the city alleging that men and women were kissing and engaging in other such 'immoral' acts inside the restaurant. This attack was reported widely in news media and social media and it triggered a wide range of social media uproar. As a response to the attack, a group of people conducted what came to be called 'Kiss of Love' protest in marine drive at Kochi. In the protest, the participants of different genders kissed each other to assert the right to express love in the public. Few days after, same kind of protest happened at Kozhikode city also. There were conflicting opinions from different quarters on this form of protest as this was something new and there was a general sense of confusion as to what should be a progressive and acceptable standpoint towards this protest and the whole issue of privacy, freedom of the expression of love, etc. The protest in Kozhikode city turned into violence with the said outfit attacking the protestors and the police arresting away the protestors. Similar protests in solidarity with the 'Kiss of love' in Kerala happened in some central universities and also in major Indian cities like Delhi and Chennai.

This protest series can be seen as attesting to the coming into being of a robust urban imagination and as part of the attempts to redefine politics by bringing in new issues which were hitherto unfamiliar to the political language of the region. The commodification of labor power as part of increasing capitalist penetration in the subcontinent plays a major role in redefining one's relationship with one's own body. It demands the dissolution of the control exercised by all other intermediary agencies and the engendering of an individual ownership of the body. What makes this complex is the fact that the demand for the non-interference of the logic of community affiliation within the sphere of privacy constituted by the autonomous individual subjects also carries with it an anxiety over non-individuated masses and lower classes. In this regard, Navaneetha Mokkil's (2019) analysis of the super hit film Drishyam (Joseph, 2013) is significant as it juxtaposes the film to Kiss of Love protests. Mokkil suggests that Drishyam can be read as a response to the hyper visibility of bodies and sexuality in the public domain mediated by new media technologies and as expressing an overwhelming concern about the circulation of women's naked bodies, unmoored from the authorised domesticity. The immense popularity of the film can be attributed to the gripping manner in which it portrayed the struggle of a family man called Georgekutty (Mohanlal) to escape the clutches of law by concealing a murder his family had to commit in their attempt to resist the machinations of a young boy who blackmailed them with a naked video of Georgekutty's teenage daughter. Mokkil argues that the 'energies that drive Drishyam anticipates the Kiss of Love type display of sexuality which is at once unauthorised and out of place but also mediated by unruly technologies'(pp. 2). She points to how Drishyam produces a metanarrative about the titillation and danger of new media forms and its reconfiguration of bodies and spaces (pp. 4). However, it can be suggested that the mediation of the digital technology networks, unmooring of women's bodies from patriarchal enclaves and their circulation as autonomous entities are inseparable from the emergence of a hegemonic urban subject. This subject's relationship to body is redefined in terms of the commodification of 
labour power as part of the capitalist expansion and hence can pose itself against those social relations which have still not entered this new relationship to body. Hence, those sections that have not yet entered this new domain of individual existence can be counted as hurdles to the corresponding regimes of privacy constituted by this domain.

In Chappa Kurishu, the whole city turns out to be a perplexing landscape for Arjun as soon as he confronts the presence of his 'other' within it. In his attempt to get back his phone from Ansari, he goes to places in city he would never have gone otherwise. Though the conflict in the movie develops around the accident by which Arjun's phone reaches Ansari's hand, it can be read as an allegorical expression of the anxiety over the spread and dissemination of technology across the masses. It is an anxiety over those who do not value the dignity of the sphere of privacy constituted by the newly emerged individual subjects. It also presents us with the problem of new commons. The idea of commons refers to those resources, natural or otherwise, accessible to all irrespective of class distinctions. Though the access and control over technology is unevenly distributed in line with the rising inequalities all over the world, there is an aspect of commons associated with technology which is projected by the dissemination of certain skills and the knowhow across class boundaries. It can be argued that Chappa Krurishu is one of the early attempts in Malayalam Cinema which posed this problematic of technology as commons and the problem of privacy in a transformed urban milieu.

\section{Video within Cinema: The Reconfigurations of the Film Form}

One interesting aspect of the intimate scene in the movie is that we also get to see the scene through Arjun's iPhone camera as if we are watching a video clip. Frederic Jameson (1991) has noted that 'video can lay claim to being post modernity's most distinctive new medium and it is a whole new form in itself' (pp. 51). Jameson's take on postmodernity asserts that far from being the cultural dominant of a wholly new social order, post modernity is only reflex of yet another modification of capitalism itself (pp. 43). The past three decades of capitalism in India have brought to the center a cultural environment which enables a new kind of subjectivity to emerge. The preponderance of video as the dominant medium of the time is attested by the phenomenon of 'video virality' which characterizes our cultural present. The proliferation of videos is accentuated by various platforms like YouTube and new applications like Tiktalk. If the representation of intimacy and sexual act was constrained in cinema, video was the form which satisfied this requirement with platforms like YouTube providing 'hot videos' and a numerous pornography sites supplying porn videos, available for larger consumption with the spread of internet. With a change in the ideological basis of cinematic form in tandem with transformations effected by global capitalism, these different logics overlap. The cinema appropriates features which were hitherto limited to video form whereas video can appropriate characteristic elements of cinema including the narrative elements of realism and melodrama. The short duration of the video compared to cinema leads to its wider and faster circulation in the new scenario keeping pace with the new fastness of life. The bedroom scene in Chappa Kurishu has the structure of a video clip as we also see the scene through the Arjun's iPhone camera and the scene is structured like a frequently interrupted video footage. I argue that though from the perspective of the story line, Arjun's use of mobile camera to record the love making sequence is the crucial portion of the 
plot, from the angle of film form this serves a different function. The interspersing of the video form between the spectator and the cinema enables the staging of the romantic activity of the couple as spectators for a moment feeling that we are watching a leaked 'hot video' and not cinema. In a transitory stage from an earlier cinematic public to a new cinematic public and an earlier spectator positioning to a new one, such a strategy must have been inevitable. In this connection, it would be fruitful to look at the discussions around the 2010 Hindi movie LSD: Love, Sex Aur Dhokha (Banerjee, 2010). An anthology consisting of three segments thematically corresponding respectively to love, sex and betrayal in the title, the film is characteristic of a new experimental multiplex aesthetics. The film was made entirely using digital formats with different cameras like handycam, amateur film camera and security camera. The film foregrounds the presence of digital technology in our lives and its bewildering mediations of everyday experience. Both the liberating and alienating elements of a penetrating camera presence are hinted at. As a formal aesthetic strategy, the whole movie is in the form of a video footage with shaky camera movements, poor framings and shabby editing typical of such footage. In his discussion of the film, Anuja Jain (2016) has pointed to the disorienting effect such a strategy makes sure for the film. As the framing and camera movements place the spectators too close to the characters, the possibility of identification is negated by drawing our attention constantly to the third body in the equation, that of camera. Though we are brought close to the characters, the film denies an anchor for the spectator. Jain sees this as allowing the film 'to create a meta-critical space to engage with the forms of spectatorship posited by the new media ecologies and marked by new arrangements of value and sensation' (pp. 13). Following Jain's arguments, one can think of this film as capturing the unsettling effects of digital technology's mediations in our everyday lives saturated by hyper visuality and also as a commentary on the decline of the ideological coherence of an earlier film form.

In fact, Chappa Kurishu was entirely shot on a digital still camera in a first attempt of its kind in Malayalam cinema. It is as if the film bears the marks of the extra-diegetic aspects of technological mediation and dissemination of social media and leaves for us a glimpse of the disintegration of the earlier formal unity of cinema. The spectator is no longer fully placed outside of cinema, they are also within the cinema. This is illustrated by characters themselves turning into spectatorial positions, occupying slots of voyeurism as in Chappa Kurishu. We already talked about Arjun's voyeurism of his own love-making act. But also significant is how Ansari tricks Arjun each time the latter comes closer to him to get his phone back. Ansari hides from Arjun each time and spies on the latter's movements. The transformed city of Kerala, where the forms of anonymity and individualism have finally triumphed, has enabled a city aesthetics in which voyeurism is an implicit factor, of which Chappa Kurishu is but a turning point. The separate slots occupied by the spectators and film makers are no longer there. All of us, including the performers and film makers, are structurally spectators and the film form is mediated by the saturation of other forms like video.

\section{Conclusion}

I have been discussing a crucial moment in the recent history of Kerala when the urban transformations and corresponding subjective transformations were eloquently pronounced in the domain of cinema. The changes brought about by globalization and the dissemination of digital technology has unleashed new forms of life with their own attendant contradictions. 
9 | Ideological Reconfigurations: Privacy, Voyeurism and Form in Recent Malayalam Cinema

Contestations over the notions of public and private, conflicting ideological logics of different cinematic publics and the question of visual and aesthetic forms are the factors I looked at in my attempt to figure out the contours of the contemporary urban life. Chappa Kurishu, the movie I discussed in some detail, has its antecedents and many of its tendencies have known development in the recent years. I have limited my reading to Chappa Kurishu as part of symptomatic reading of a transformation. The division of spectatorial positions, attempts to define the spectator as urban, contesting logics of different cinematic publics, representation of the private by introducing the voyeuristic relation are some of the coordinates within which I sought to place my analysis to claim that the questions of cinema today are also questions of city and urban subjectivity.

\section{Funding Disclosure/Acknowledgement}

I declare that no funding has been received for research and/or publication

\section{References}

Athique, A. (2011). From cinema hall to multiplex: A public history. South Asian Popular Culture, 9(2), 147160. https://doi.org/10.1080/14746681003798037

Banerjee, D. (Director) (2010). Love Sex aur Dokha. [Motion Picture] India: Hindi

Han-min, K. (Director) (2009). Handphone. [Motion Picture] South Korea: Korean.

Jain, A. (2017). Love Sex Aur Dhoka: a new morphology of contemporary Bombay cinema. Screen, 58(1), 98-106. https://doi.org/10.1093/screen/hjx010

Jameson, F. (1991). Postmodernism or the Cultural Logic of Late Cpitalism. Duke University Press.

Joseph, J. (Director) (2013). Drishyam [Sight]. [Motion Picture] India: Malayalam.

Metz, C. (1983). Psychoanalysis and Cinema: the Imaginary Signifier (Language, Discourse, Society) (1983rd ed.). Palgrave Macmillan.

Mokkil, N. (2018). Anxieties of Seeing: The Sensational World of Cinema, Digital Media and Politics. BioScope: South Asian Screen Studies, 9(2), 165-183. https://doi.org/10.1177/0974927618813478

Mulvey, L. (1975). Visual Pleasure and Narrative Cinema. Screen, 16(3), 6-18. https://doi.org/10.1093/screen/16.3.6

Prasad, M. M. (2001). Ideology of the Hindi Film: A Historical Construction (2000th ed.). Oxford University Press.

Radhakrishnan, R. (2017). Urban/the City: An Experiment Called the "Kochi Film." Positions, 25(1), 173-194. https://doi.org/10.1215/10679847-3710391

Radhakrishnan, R. (2010). Soft Porn and the Anxieties of the Family. In M. T. Pillai (Ed.), Women in Malayalam Cinema: Naturalising Gender Hierarchies (pp. 194-220). Orient Blackswan.

Rasheed, A. (Director) (2005). Rajamanikyam. [Motion Picture] India: Malayalam.

Thahir, S (Director). (2011). Chappa Kurishu [Head or Tail]. [Motion Picture] India: Malayalam. 
10 | Rupkatha Journal, Vol. 13, No. 4, 2021

Times of India. (2014, November). The "Kiss of Love" campaign. https://timesofindia.indiatimes.com/thekiss-of-love-campaign/photostory/45108971.cms

Varghese, M. A. (2017). Vikasanam: The Expansionist Choreography of Space-Making in Kerala. In T. Kuldova \& M. A. Varghese (Eds.), Urban Utopias: Excess and Expulsion in Neoliberal South Asia (pp. 74-95). Palgrave Macmillan.

B. Abhijith is a research fellow in the Department of Cultural Studies in EFLU, Hyderabad. His areas of interests include Urban Studies, Malayalam Cinema, Kerala Modernity and Popular Culture. You can mail him at aabhinov.91@gmail.com 